Rabaska

Revue d'ethnologie de l'Amérique française

\title{
Le Centre de conservation du Québec
}

\section{Patrick Albert}

Volume 14, 2016

URI : https://id.erudit.org/iderudit/1037493ar

DOI : https://doi.org/10.7202/1037493ar

Aller au sommaire du numéro

Éditeur(s)

Société québécoise d'ethnologie

ISSN

1703-7433 (imprimé)

1916-7350 (numérique)

Découvrir la revue

Citer ce document

Albert, P. (2016). Le Centre de conservation du Québec. Rabaska, 14, 306-307.

https://doi.org/10.7202/1037493ar

Ce document est protégé par la loi sur le droit d'auteur. L’utilisation des services d'Érudit (y compris la reproduction) est assujettie à sa politique d'utilisation que vous pouvez consulter en ligne.

https://apropos.erudit.org/fr/usagers/politique-dutilisation/
Cet article est diffusé et préservé par Érudit.

Érudit est un consortium interuniversitaire sans but lucratif composé de l’Université de Montréal, l'Université Laval et l'Université du Québec à Montréal. Il a pour mission la promotion et la valorisation de la recherche. https://www.erudit.org/fr/ 


\title{
QuÉBEC
}

\section{Le Centre de conservation du Québec}

\author{
1825 , rue Semple \\ Québec (Québec) \\ G1N 4B7
}

\author{
Téléphone : (418) 643-7001 \\ Courriel : ccq@mcc.gouv.qc.ca \\ Toile : www.ccq.gouv.qc.ca
}

Le Centre de conservation du Québec ( $\mathrm{CCQ}$ ) a connu une intense période d'activités au cours de la dernière année. Voici un résumé des principaux événements.

\section{Publications}

Le CCQ a réalisé, en collaboration étroite avec quelques-uns de ses partenaires institutionnels, plusieurs publications. Parmi celles-ci, mentionnons :

- Le Centre de conservation : Lever le voile du temps, un numéro spécial de la revue Continuité qui présente un florilège d'une vingtaine des chroniques rédigées par les restaurateurs du Centre parues dans la revue au fil des ans ; un portrait édifiant du travail réalisé au CCQ.

- Les Tabernacles du Québec des XVII et XVIII siècles, un ouvrage majeur rédigé par Claude Payer, restaurateur au CCQ, et Daniel Drouin, conservateur au Musée national des beaux-arts du Québec. Publié par les Publications du Québec, cet ouvrage de référence livre une véritable histoire de la sculpture au Québec, vue à travers le meuble le plus précieux des églises, en montrant notamment les filiations entre les œuvres des sculpteurs de Québec, de Trois-Rivières, de Montréal et d'ailleurs.

- Un Guide sur les toitures en bardeaux de bois, par Mireille Brulotte et Patrick Quirion, restaurateurs à l'atelier bois, est à paraître aux Publications du Québec à la fin de 2016. Il offrira aux spécialistes des bâtiments anciens une somme remarquable de connaissances techniques développées sur ce sujet au cours des vingt dernières années.

\section{Congrès}

L'expertise du CCQ a été sollicitée à l'occasion du Congrès international de l'Association pour la préservation et ses techniques (APT), qui a rassemblé à Québec quelque huit cents professionnels, scientifiques et praticiens du domaine, en octobre 2014. Les restaurateurs du C CQ ont présenté plusieurs conférences et ateliers sur les techniques de restauration touchant aux éléments architecturaux des bâtiments. Cette première collaboration a généré des retombées, notamment par la présentation à Trois-Rivières d'une conférence sur les finis anciens par Isabelle Paradis, restauratrice au CCQ, à un auditoire composé essentiellement de membres de l'APT. D'autres projets sont en gestation avec ce regroupement international d'architectes et autres spécialistes du patrimoine bâti.

Plusieurs restaurateurs du CCQ ont été conférenciers au premier congrès international conjoint organisé par l'Association canadienne de conservation et restauration des biens culturels (ACCR) et l'American Institute for Conservation (AIC), qui a eu 
lieu à Montréal en mai 2016 et dont le thème général était la prévention et la gestion des risques liés à d'éventuels sinistres et le sauvetage des collections endommagées à la suite de sinistres.

\section{Des milliers de dossiers}

Depuis plus de trente-cinq ans, les spécialistes du CCQ ont développé une connaissance inégalée des objets d'art et des biens culturels. Au fil du temps, ils ont constitué une documentation exceptionnelle sur le patrimoine mobilier du Québec. Soulignons qu'en plus des services de restauration et d'expertise, le CCQ offre aussi des formations adaptées aux besoins de ses clients.

Parmi les dossiers importants réalisés récemment, mentionnons :

- la signature d'une troisième entente de services en 2016 avec la Société de transport de Montréal (Sтм). Depuis plus de dix ans, l'expertise du CcQ contribue notamment à la restauration, la conservation et la mise en valeur de l'impressionnante collection d'œuvres d'art du métro ;

- la restauration de collections d'œuvres d'art public pour les villes de Québec et de Longueuil ;

- la restauration du maître autel de l'église Sainte-Famille de Boucherville et de celui offert par les sœurs Grises au Musée national des beaux-arts du Québec.

Le Cce continue de développer de nouveaux partenariats avec les collectivités locales, la culture étant en effet de plus en plus reconnue comme un levier incontestable de développement économique. Le Centre compte à ce jour un bon nombre d'ententes (expertise, formation, restauration) avec des clientèles de tous horizons réparties sur l'ensemble du territoire québécois, ce qui augure de belles perspectives tant pour le Centre de conservation du Québec que pour le patrimoine québécois !

PAtrick Albert

\section{Centre Mnémo}

255, rue Brock, local 426

Drummondville (Québec)

J2C $1 \mathrm{M} 5$
Téléphone : (819) 472-3608

Télécopieur : (819) 477-5723

Courriel : centre@mnemo.qc.ca

Toile : www.mnemo.qc.ca

\section{A. Diffusion}

\section{Bulletin Mnémo}

Depuis l'année dernière, le Bulletin Mnémo a fait paraître les articles suivants : « La danse à Natashquan », une entrevue avec Bérangère Landry, par Pierre Chartrand ; «Transmission de la danse traditionnelle en Nouvelle-Acadie » par Philippe Jetté ; « Le projet M'en allant jeunesser! » par Monique Lebossé et Paul Marchand ; «Les violoneux français d'Amérique et le grand concours international de 1926 à Lewiston, Maine » par Jean Duval ; «Frank H. Norman : un homme de son temps » 